\title{
Turismo ferroviário em Portugal nos anos de 1930
}

\author{
Railway tourism in Portugal in the 1930 s
}

\author{
Carla Ribeiro \\ Escola Superior de Educação do Politécnico do Porto, Portugal \\ carlaribeiro@ese.ipp.pt
}

\begin{abstract}
Resumo
O advento da contemporaneidade no mundo ocidental tornou indiscutível a importância do turismo, desde logo objeto de atenção política. Portugal comungou deste fenómeno, através de um investimento no turismo interno conseguido, em grande parte, graças aos caminhos-de-ferro, o que permitiu alargar a rede de potenciais turistas nacionais. Este artigo, de natureza teórica e histórica, centra-se em duas iniciativas de incentivo às viagens ferroviárias turísticas no período de 1930 - os comboios mistério e os expressos populares - recorrendo-se para tal ao estudo de caso. Analisando as suas origens, formatos e intenções, defende-se a tese de que os exemplos estudados constituíram parte integrante de uma política de identificação da população com os projetos político-ideológicos de Nação veiculados pela I República e pelo Estado Novo.
\end{abstract}

Palavras-chave: turismo ferroviário; comboios mistério; expressos populares.

\begin{abstract}
With the emergence of modernity in the Western world, tourism became undeniably important, immediately becoming an object of political attention. Portugal shared this phenomenon, through the development of domestic tourism travel thanks largely to the expansion of the national railway grid, which increased the number of potential domestic tourists, especially in the 1930s. This paper, of a theoretical and historical nature, will focus on two initiatives from the 1930 aimed at promoting railway tourism travel - mystery trains and popular trains - using a case study methodology. By analyzing the origins, formats and intentions of these initiatives, it is argued that the examples under study are components of a policy that seeks an identification of the population with the political and ideological projects of the First Republic and the Estado Novo.
\end{abstract}

Keywords: railway tourism; mystery trains; popular trains.

\section{Introdução}

O século XX nasceu, na Europa, sob o signo da insegurança, afastado das certezas de progresso indefinido da centúria de Oitocentos, situação agravada com a I Guerra Mundial. Uma Europa que, no pós 1918, sofreria, no plano económico, as sequelas geradas pela crise de 1929 e pela Grande Depressão e, no plano político, assistiria à consolidação de ditaduras fascistas, totalitárias e nacionalistas.

Num momento, o da década que precede a II Guerra Mundial, de crise, aumento do desemprego e acentuação dos antagonismos nacionais, a criação do Bureau International du Travail, secretariado permanente da Organização Internacional de Trabalho (OIT), reflete uma outra preocupação, relativa à organização dos tempos livres dos trabalhadores, interesse que, sublinhe-se, teria relação com a ideia de redução dos horários de trabalho como solução para

Dos Algarves: A Multidisciplinary e-Journal, $30-2017$.

ISBN 2182-5580 @ ESGHT - University of the Algarve, Portugal.

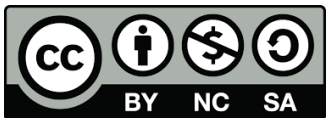

To cite this article: Ribeiro, C. (2017). Turismo ferroviário em Portugal nos anos de 1930. Dos Algarves: A Multidisciplinary e-Journal, 30,18-30. doi: 10.18089/DAMeJ.2017.30.2 
absorver o enorme volume de desemprego que então assolava o mundo ocidental (Valente, 2010).

Na década de trinta, entre 1930 e 1935, os diversos congressos internacionais organizados pela OIT centram-se cada vez mais na questão dos lazeres dos trabalhadores, na ideia de que "todos os povos, todas as classes sociais têm interesse, o maior interesse, em que o trabalhador sinta, na mais ampla medida do possível, alegria de viver. Ele precisa do seu quinhão de diversões. Adotará diversões triviais se nada se fizer para situar no seu ambiente, ao seu alcance, diversões mais dignas" (citado em Thiesse, 2001: 370). Discute-se qual o papel do Estado, com as posições dividindo-se entre o modelo demoliberal, que preconizava a liberdade de organização destes tempos livres e o afastamento do Estado como agente interventor, e os modelos autoritários, que defendiam a organização centralizada das políticas de lazer dos trabalhadores. Neste último caso temos a Itália e a Alemanha, e os organismos Opera Nazionale Dopolavoro (OND) e Kraft durch Freude (KdF), fundados respetivamente em 1925 e 1933. Embora com modelos diferentes, têm como missão organizar atividades culturais, desportivas e recreativas para os trabalhadores, trabalhando em parceria ou absorvendo as coletividades já existentes ${ }^{1}$.

Neste contexto, "a viagem constituía o meio privilegiado de conferir uma qualidade nova ao tempo de lazer" das classes populares (Richez \& Strauss, 2001: 474), entendida no sentido da reconciliação com a natureza e de regeneração do corpo, assente em discursos de teor higienista, de louvor das virtudes do ar puro para o apuramento da raça e como forma de retemperar o trabalhador da natural fadiga do trabalho. Desta forma, pode mesmo afirmar-se que "o tempo de lazer tornava-se assim, paradoxalmente, um elemento constitutivo do tempo de trabalho" (Richez \& Strauss, 2001: 471). Mas este tempo de ócio na sua versão de retorno à natureza trazia igualmente consigo "um desejo de apropriação de um país, de encontro físico com a nação em todo o seu espaço, pela aprendizagem da variedade das suas paisagens e da sua história, materializada nos monumentos. O tempo das viagens era também um tempo patriótico e político" (Richez \& Strauss, 2001: 475-476).

E é esta componente política do tempo de lazer e da viagem que justifica a atuação privilegiada do Estado em vários países europeus: um dos objetivos primordiais deste turismo estatal popular seria o de alimentar uma ideia de coesão nacional.

Todavia, no início do século XX, nos países europeus industrializados, o turismo permanecia, em geral, privilégio dos estratos sociais mais abastados. Fatores como a criação de sociedades incentivadoras das práticas de lazer e turismo, a publicação de guias e roteiros de viagens e o desenvolvimento dos transportes darão um importante contributo para o alargamento do turismo a grupos cada vez mais amplos. Note-se que a construção da rede de caminhos-de-ferro nos principais países europeus permitiu uma maior mobilidade das populações, percorrendo-se maiores distâncias em menor tempo e tornando acessível a um maior número de pessoas as viagens de lazer e turismo. Por outro lado, "as próprias companhias de caminho de ferro viam no turismo uma forma de aumentar a utilização do transporte ferroviário e contribuir, assim, para obter a retribuição do capital investido na construção da rede ferroviária" (Matos, 2014: 1018).

Em Portugal, na primeira década do século XX, a problemática do direito ao descanso e dos tempos livres dos trabalhadores começava igualmente a ter expressão política, em particular na propaganda dos republicanos. Quanto ao turismo, apesar de ter ganho maior dinamismo desde a realização, em Lisboa, em maio de 1911, do IV Congresso Internacional de Turismo, era ainda privilégio das elites. Assim, a concretização do aproveitamento dos tempos

\footnotetext{
${ }^{1}$ Para as duas organizações, o turismo popular foi uma das áreas de atuação privilegiadas, destacandose, na Alemanha, por exemplo, os famosos cruzeiros marítimos na frota privada da Kdf, em navios de classe única.
} 
livres dos trabalhadores e, consequentemente, o alargamento de práticas de turismo a camadas mais amplas da população portuguesa, só será objeto de intervenção estatal a partir de 1935, com a criação da Fundação Nacional de Alegria no Trabalho (FNAT). Até lá, será a iniciativa privada a predominar, em particular a partir de 1924, com a criação da Federação das Sociedades de Educação e Recreio.

Chegados então aos anos trinta, no geral, a imprensa nacional defendia que, apesar do turismo proporcionar uma bem-sucedida propaganda externa - "A propaganda do nosso país lá fora, é feita já hoje inteligentemente, havendo factores importantes a considerar, que tornam o nome de Portugal conhecido de todo o Mundo" - não parecia ter causado os mesmos efeitos internamente: "As belezas do nosso país necessitam primeiro que tudo ser reclamadas entre nós, pois a maioria dos portugueses que viajam não conhecem ainda o seu torrão [...] não conhece o seu país" (Costa, 1932: 336). Neste sentido, pugnava-se repetidamente para que "Portugal seja mais conhecido dos portugueses, e se dê para baixo nesse vício [...] de se elogiar o 'lá fora' turístico e pitoresco", preenchendo-se desta forma aquilo que era considerado como "uma lacuna no nosso meio social” (Ferreira, 1932a: 144).

Colocam-se assim duas grandes questões de investigação: como se deu resposta a estas pretensões, por um lado e, por outro, qual o papel desempenhado pelos caminhos-de-ferro nacionais?

Na tentativa de responder a estas interrogações, após a contextualização das questões do turismo e do turismo popular na Europa do período entre guerras, aborda-se primeiramente a organização do turismo português, entre sensivelmente 1910 e 1940, e a importância que lhe era conferida, seguindo-se uma panorâmica do desenvolvimento do turismo ferroviário em Portugal, destacando-se o papel relevante da Gazeta dos Caminhos de Ferro, analisando-se então em pormenor os estudos de caso em questão.

Considera-se, assim, que este artigo poderá contribuir para o conhecimento do turismo português no período em análise, em particular do turismo ferroviário, dada a ausência de estudos específicos e de fundo sobre a temática. Com efeito, e em particular sobre iniciativas de turismo ferroviário como as analisadas, existem tão somente referências pontuais em investigações mais generalistas. Procura-se deste modo apresentar informações mais detalhadas sobre as duas iniciativas em questão, fornecendo novos dados e contribuindo para colmatar uma lacuna na historiografia referente ao turismo ferroviário português.

\section{Opções metodológicas}

No intuito de dar resposta às questões acima referidas, neste artigo, de caráter predominantemente teórico e histórico, procede-se à análise de duas iniciativas específicas de incentivo às viagens turísticas ferroviárias de cariz popular, os comboios mistério e os expressos populares. As questões de investigação apresentadas permitirão, desta forma, criar um quadro de leitura, reconstituindo as narrativas então geradas: Em que consistiam estas viagens? A que público(s)-alvo se destinavam? Quais os principais roteiros de viagem? Que adaptações sofreu este modelo importado? Que correspondência existiu entre os objetivos traçados e as realizações efetivas? Crê-se que a resposta a este conjunto de perguntas permitirá defender a tese de que estas duas práticas turísticas constituíram-se, acima de tudo, como parte integrante de uma política de construção identitária, quer da I República, quer do Estado Novo, procurando a identificação da população com estes projetos político-ideológicos de Nação.

Em termos metodológicos, numa prática que se pretende de micro-história, optou-se pelo estudo de caso, recorrendo-se à análise do discurso como método de análise de informação. Considerando a escassez de estudos historiográficos especializados em turismo ferroviário 
entre nós ${ }^{2}$, optou-se sobretudo por fontes históricas, sendo que as atenções recaíram sobre a imprensa periódica da época - em particular a especializada nas questões ferroviárias e turísticas, uma vez que constitui uma prolífica fonte de informação, relatando fatos, discutindo e pronunciando-se sobre a realidade nacional no que concerne a estes assuntos - e nos discursos e escritos de personalidades ligadas ao turismo e à ferrovia nacional, fontes que permitem desenhar de forma mais nítida o debate nacional então em curso, relativamente ao papel e à importância dos caminhos-de-ferro para o turismo interno português, permitindo reconstituir as práticas bem como as narrativas.

\section{Portugal e o turismo: Organização e importância}

Parece ser ponto assente que o turismo é um dos setores de maior importância na economia de vários países, nos quais se engloba Portugal. Apontado já em 1898, por Anselmo de Andrade, como a atividade a desenvolver no sentido da recuperação económica nacional, só em 1911, durante o Governo Provisório da República, se instituíram as primeiras estruturas oficiais de turismo. Com efeito, logo a 18 de maio de 1911, e decorrente dos trabalhos do IV Congresso Internacional de Turismo da Federação Franco-Hispano-Portuguesa de Sindicatos de Iniciativa e Propaganda, realizado em Lisboa, na Sociedade de Geografia, o Governo Provisório decretou a constituição, no Ministério do Fomento, de um Conselho de Turismo coadjuvado por uma Repartição de Turismo, dotada de autonomia administrativa e financeira. Em 1920, extinguiu-se o Conselho de Turismo e integrou-se no Ministério do Comércio e Comunicações a Repartição do Turismo. Entretanto, a Ditadura Militar surgida do golpe de 28 de maio de 1926 colocou a Repartição de Turismo dependente, a partir de 1927, do Ministério do Interior, situação que perdurou até finais de 1939, altura em que, pelo decreto $n^{\circ} 30251$, de 30 de dezembro, se providenciava a passagem, a partir de 1 de janeiro de 1940, das competências do Ministério do Interior em matéria de turismo para o Secretariado de Propaganda Nacional (SPN), então dirigido por António Ferro.

Data igualmente deste período, mais concretamente de 1921, a abertura em Paris da primeira representação do turismo nacional no estrangeiro, gerida pelo Estado e pela Companhia Portuguesa dos Caminhos de Ferro, e a criação das Comissões de Iniciativa, base das estruturas orgânicas locais. Este aparelho administrativo do turismo irá consolidar-se até meados da década de trinta, com a criação das Casas de Portugal. Em 1934, o Automóvel Clube de Portugal (ACP) organizou um Centro de Turismo Português, passando a representar o país na prestigiada Alliance Internationale de Tourisme ${ }^{3}$ e, no ano seguinte, é criada a FNAT, que se ocupava do turismo social, através de excursões populares, e instituído o Conselho de Turismo do Ministério dos Negócios Estrangeiros.

Apesar desta pluralidade de organismos e do fato de o turismo ser assunto de vivo interesse e aceso debate, era consensual a importância que lhe era atribuída: a de uma atividade económica que pretendia atingir uma franja cada vez maior da sociedade e da qual se esperavam grandes lucros. Assim, José de Ataíde, chefe da Repartição de Turismo, apresentava este campo de atividade como "um dos agentes que mais eficazmente devem

\footnotetext{
${ }^{2}$ A investigação académica em torno do tema do turismo ferroviário em Portugal no período em análise é, como se referiu, escassa, sendo este um assunto pouco abordado, com estudos parcelares, de pouca extensão e profundidade, destacando-se os artigos de Elói Ribeiro - Gazeta dos Caminhos de Ferro e a promoção do turismo em Portugal (1888-1940). Biblio 3W. Revista Bibliográfica de Geografía y Ciencias Sociales, XIV (837) - e de Ana Cardoso Matos e Maria Luísa Santos - Os Guias de Turismo e a emergência do turismo contemporâneo em Portugal (dos finais do século XIX às primeiras décadas do século XX). Scripta Nova. Revista Electrónica de Geografía y Ciencias Sociales. VIII (167).

3 Criada em 1898, com o intuito de agrupar os clubes de turismo de vários países, foi a primeira organização internacional de turismo.
} 
influir na reconstrução económica do país" (Ataíde, 1931: 18). Nesta mesma linha de pensamento se inscreviam as visões de outros protagonistas no campo turístico, como Joaquim Roque da Fonseca, diretor da Associação Comercial de Lisboa e membro das Comissões de Turismo do ACP e do Ministério dos Negócios Estrangeiros, que defendia que "o turismo pode e deve ser para nós o mesmo que é para a França, para a Itália e para a Suíça - a maior das grandes indústrias nacionais" (Fonseca, 1932: 39).

Todavia, quando o setor do turismo passa para a alçada do SPN e de António Ferro, a perspetiva adotada é de cariz nacionalista e não tanto economicista, defendendo-se um turismo que funcionasse como instrumento privilegiado de promoção e propaganda do regime - "Se o turismo é um problema sério, e não um simples passatempo, é porque está ligado, directa e indirectamente, a quase todos os problemas nacionais [... ], meio seguríssimo não só de alta propaganda nacional como de simples propaganda política (Ferro, 1949: 34) - e de manutenção da ordem interna, do consenso nacional: "O turismo constituiu sempre, em toda a parte [... ] uma excepcional terapêutica moral, [sendo que] os grandes países visitados que fazem da indústria de receber visitas uma fonte de riquezas e de renovação nacionais são países de ordem e de convívio exemplares: a Suíça, a Holanda, a Bélgica" (Ferro, 1939: 1). Desta forma, o turismo nacional foi claramente assumido, neste período, como arma de propaganda político-ideológica do Estado Novo, instrumento privilegiado para o reconhecimento internacional do regime, por um lado e, por outro, estratégia de inclusão dos cidadãos nos ideais e princípios do regime de Salazar, ordeiro e respeitador.

\section{O desenvolvimento do turismo ferroviário em Portugal}

Foi no século XIX que a viagem turística sofreu um desenvolvimento sem precedentes, num período de evolução dos costumes. A partir da década de 1840, o alargamento da rede de caminhos-de-ferro trouxe consigo uma alteração importante em termos de turismo: por um lado, porque tornou acessível a um maior número de pessoas as viagens de lazer e, por outro, porque os locais que passaram a ser considerados como destino dos turistas foram determinados pela própria rede de caminhos-de-ferro. Com efeito, o caminho-de-ferro tornou as viagens mais rápidas, mais seguras, mais cómodas e mais baratas. A grande diversidade de iniciativas promocionais, a redução de preços dos bilhetes, as campanhas publicitárias de divulgação de locais de interesse turístico, tudo isto proporcionou o alargamento da viagem turística às classes médias, num esforço de "tornar conhecido Portugal aos portugueses" (Ferreira, 1932a: 144).

Em particular, as companhias de caminhos-de-ferro seguiram uma estratégia comercial de incentivo às viagens ao estabelecerem uma grande variedade de tarifas especiais: os comboios de recreio entre Lisboa e o Porto, criados em 1860, propondo reduções dos preços dos bilhetes em épocas festivas ou de banhos; as tarifas especiais nas épocas balneares e termais, para bilhetes de ida e volta com uma validade de 60 dias; as tarifas especiais para grupos colegiais e professores, aplicáveis durante as férias escolares, fins de semana e feriados, estabelecidas em 1887; a organização de viagens para acontecimentos particulares, tais como exposições, congressos e feiras, e para destinos e monumentos de interesse turístico; as viagens circulatórias, ou seja, itinerários propostos em Portugal (três itinerários criados em 1889), em Portugal e Espanha (dois itinerários criados em 1891 com duração de 60 e 80 dias respetivamente, ambos com partida de Lisboa) ou pela Europa. Para além destes exemplos, as próprias companhias de caminhos-de-ferro chegaram a associar-se entre si para oferecer 
melhores condições de mobilidade aos utentes. Desde logo, a tarifa combinada de bilhetes de excursão e, a partir de 1906, os bilhetes quilométricos, que constituíam opções de viagem onde o preço dependia dos quilómetros a percorrer e os passageiros podiam escolher livremente diversas combinações de itinerários. Nos inícios do século XX, destacava-se a realização de excursões a vários pontos do país: ao Algarve, no florir das amendoeiras, à Serra da Estrela, para a prática de desportos de inverno, a Tomar, para se assistir à Festa dos Tabuleiros, etc. Estas excursões eram muitas vezes organizadas em colaboração com as Comissões de Iniciativa locais e serviços de autocarro (Matos, Ribeiro \& Bernardo, 2009).

A promover e divulgar estas iniciativas, aparece-nos a Gazeta dos Caminhos de Ferro, ${ }^{4}$ que contribuiu de forma efetiva para a promoção turística do país, em rubricas como "Notas de viagem", "Propaganda de Portugal”, "Viagens no país", "Excursões no país", "Páginas de turismo”, “Portugal turístico”, “Portugal país de turismo”, “Crónicas de viagem”, publicando artigos sobre as linhas de caminho de ferro com interesse turístico, descrevendo paisagens, monumentos, aspetos etnográficos e estâncias termais e balneares.

Após um período de crescimento de passageiros turísticos nos caminhos-de-ferro portugueses, em parte graças às mencionadas iniciativas das companhias, a I Guerra Mundial seria um período de quebra. Verificou-se a subida generalizada dos preços, o que causou a atribuição de sobretaxas, a pedido das empresas ferroviárias, no preço dos bilhetes vendidos. Com a publicação da lei das oito horas de trabalho, agravaram-se as tensões sociais, com inúmeras greves e o encerramento das oficinas da CP em 1922, com repercussões na imobilização do parque motor. A tudo isto juntou-se a concorrência do automóvel, com índices de crescimento exponencial com a criação da Junta Autónoma da Estradas, em 1927. Assim, no início dos anos trinta, as receitas do tráfego ferroviário estavam em regressão. Tornava-se imperativo procurar "os meios necessários de obter compensação para essa quebra de receitas” (Niza, 1933: 72).

E foi o advento do Estado Novo que veio mudar esta situação de crise, verificando-se desde logo um grande empenho oficial na produção e na divulgação de atividades turísticas para as quais se pretendia atrair um público de fracos recursos económicos, preocupação resultante da necessidade do regime em controlar os tempos livres das camadas mais desfavorecidas da sociedade portuguesa, mais do que da vontade em proporcionar momentos turísticos e de lazer. Esta preocupação era partilhada por outros elementos afetos à vida ferroviária nacional, como um dos redatores da Gazeta dos Caminhos de Ferro, Melo e Niza, que defendia excursões em comboios para as classes menos abastadas como meio de promover "uma distracção sã que faça desviar uma grande parte do público de maus hábitos radicados" (Niza, 1933: 72).

Os caminhos-de-ferro desempenharam, desta forma, um papel relevante na estratégia do regime, organizando viagens e excursões que transportassem as massas que habitavam "nos bairros sem higiene ou conforto" das cidades, aqueles que "conhecem o prazer por informação e a desventura por experiência", para que pudessem "visitar cidades, contemplar

\footnotetext{
${ }^{4}$ A Gazeta dos Caminhos de Ferro teve início em março de 1888, estendendo-se a sua publicação até 1971. Nas suas páginas temos informação e documentação da maior relevância para a história dos caminhosde-ferro, na sua globalidade, pois abordam os mais diversos aspetos: tarifas de transporte, informação sobre as linhas em Portugal, nas colónias e no estrangeiro, descrições de viagens, relatórios e contas das diversas companhias, cotações dos títulos de caminhos-de-ferro nas bolsas de Lisboa e Porto, receitas, despesas, legislação, estatística, publicidade, turismo, obras públicas, etc. Ao longo da sua existência, a Gazeta contou com a colaboração de um leque de homens públicos, todos personalidades ligadas ao meio ferroviário, dos transportes e das obras públicas (Correia, 2009).
} 
paisagens e admirar monumentos que muito e muito interessam à nossa sensibilidade e ao nosso patriotismo" (Manso, 1933: 1).

\section{Os comboios-mistério}

Passado o período de menor vitalidade do turismo ferroviário, na sequência da I Guerra Mundial e da crise de 1929, em 1932 volta a surgir uma iniciativa digna de registo, pela Companhia Portuguesa dos Caminhos de Ferro. Trata-se dos comboios mistério, que mimetizava o que se fazia no estrangeiro, nomeadamente em Inglaterra e nos Estados Unidos da América, donde esta iniciativa era originária.

A ideia era simples: considerando que "muita gente não viaja, não sai aos sábados de Lisboa, porque não sabe para onde ir", perdendo "tempo e energia buscando nos recantos da memória um itinerário que nunca encontra” (Sabel, 1932: 315), a particularidade dos comboios mistério residia na omissão do destino e do percurso das viagens, que constituíam uma surpresa para os viajantes. Assumia-se, desta forma, como uma forma de fazer turismo mais atrativa, face a outros modelos: "É uma maneira nova de fazer turismo, não o turismo à inglesa, mecânico, estilo 'guide Jeanne', de bonecas e mulheres em fila [...] que já sabem de antemão o que vão ver, os locais, as igrejas, os hotéis; enfim, o turismo Taylorizado, sem surpresas" (Sabel, 1932: 315).

Embora fosse o mistério relativo ao destino da viagem um dos atrativos desta iniciativa, o primeiro relacionava-se com os preços praticados, conforme noticiado na imprensa da época: "Felicidade cara, felicidade apenas acessível aos ricos? De modo algum! Felicidade a preços inverosímeis, felicidade ao alcance de todas as ambições. Por duzentos escudos, com todas as despesas compreendidas, pode o sonho ser vivido em primeira classe. Por $175 \$ 00$ pode a viagem ser feita em segunda classe" (“Uma iniciativa original da C.P.", 1932:1).

A ideia era saudada calorosamente, pelas diversas finalidades que nela se entreviam: "Ela pode contribuir, notavelmente, para modificar os hábitos dos portugueses, que sofrem pela falta de distracções, que vivem emparedados dentro das suas profissões, para quem a vida é uma planície rasa. [...] Lançar e proteger a iniciativa dos comboios-mistério é estimular, portanto, uma alta medida de higiene moral, que muito pode contribuir para o levantamento da nossa raça” ("Uma iniciativa original da C.P.", 1932: 1). Portanto, a ideia em voga pela Europa: a da viagem como forma de apuramento da raça.

Mas outra finalidade, porventura mais importante ainda, se elogiava: "Outra vantagem tem ainda a iniciativa da C.P.: fazer conhecer Portugal aos portugueses, um Portugal escondido, que eles não conheceriam sem este empurrão, sem o estímulo da curiosidade [...] Os portugueses, que vão embarcar no primeiro comboio-mistério, são viajantes felizes: vão viajar na sua terra com a sensação, sempre agradável, de viajar no estrangeiro" "Uma iniciativa original da C.P.”, 1932: 1). Convém relembrar que se está em pleno período de afirmação do Estado Novo e que este discurso nacionalista se compatibiliza em absoluto com os objetivos políticos do regime, de consolidação da (sua) ideia de Nação.

Todavia, na Gazeta dos Caminhos de Ferro, inicialmente a iniciativa foi recebida com desconfiança, como se pode perceber da leitura do artigo de Armando Ferreira, pondo em dúvida o sucesso da ideia: "Como a maior parte das excursões só se realizam havendo um número determinado de passeantes, o que faz com que até às vésperas da partida ninguém saiba se há ou não excursão; e como o público lisboeta é desconfiado a valer, ou faz de esperto, querendo aqueles saber para onde vai e estes saberem já tudo por inconfidências... íamos apostar que o comboio-mistério em Portugal será um comboio-fiasco" (Ferreira, 1932b: 280). No número seguinte, contudo, Armando Ferreira retratava-se, afirmando: "Neste lugar, há 15 
dias, duvidámos do sucesso, tão enigmáticos e desconfiados são os portugueses; afinal a ideia foi bem acolhida, e os reclames que anteciparam a organização do comboio [...] conseguiram despertar mais de um cento de viajantes..." (Ferreira, 1932c: 304).

Acompanhando a Gazeta percebe-se que a ideia ia sendo acarinhada: "Os 'comboiosmistério' são um empreendimento simpático e moderno, que deve ser bem acolhido", escrevia-se em julho de 1932, considerando-se que, por mérito da iniciativa, "a C.P. anda agora a par do progresso mais moderno, trazendo para Portugal inovações que despertam o interesse e bem merecem o favor do público" (Costa, 1932: 337).

No verão de 1932, registam-se, pela análise da Gazeta dos Caminhos de Ferro, pelo menos nove edições do comboio mistério, demonstrando o sucesso da iniciativa, que teve, em setembro de 1932, direito a um artigo de três páginas, com fotografias, de José da Natividade Gaspar, numa cobertura jornalística inédita, da sétima destas viagens. Este comboio mistério, constituído por uma carruagem de $1^{\mathrm{a}}$ classe, uma de $2^{\mathrm{a}}$ classe e um vagão-restaurante, teve a duração de dois dias, começando por Coimbra e seguindo em direção ao norte do país, atravessando localidades como Porto, Valongo, Régua, Vila Real, Pedras Salgadas, Vidago e o Marão. De referir o hábito de as populações locais receberem com honras estes viajantes, como noticiava o repórter da Gazeta: "Às 17.17, deixa-se o comboio nas Pedras Salgadas e encaminhamos com rumo ao Parque, enquanto estrondeam nos ares amáveis morteiros e uma atenciosa cavalgada de gente local nos espera no largo da estação, em pomposa guarda de honra" (Gaspar, 1932: 406).

Já o nono comboio mistério seguiu pela linha da Beira Baixa, em direção à Serra da Estrela, passando pelo castelo de Almourol e Castelo Branco, antes de chegar à Covilhã, onde os excursionistas visitaram a fábrica da Empresa Transformadora de Lãs e foram recebidos na Câmara Municipal. De seguida, Manteigas, com uma receção dos viajantes pelo presidente da edilidade e pelos representantes das Comissões de Iniciativa de Manteigas e da Covilhã, numa "entusiástica recepção", constituída por “música, mais foguetório, palmas e vivas" (Almeida, 1932: 428). Por fim, Alpedrinha, visitada "com minúcia" e onde "a população, em massa, aguardava a chegada da caravana produzindo-se manifestações", com os visitantes "acarinhados e envolvidos em atenções" (Almeida, 1932: 428).

Mas nem só dentro de Portugal viajavam estes comboios. A Gazeta informa-nos que o quarto, de julho de 1932, permitia ver mais do que os mais belos recantos de Portugal, tendo os preços sido ligeiramente aumentados e os excursionistas avisados para irem munidos do respetivo bilhete de identidade, para uma viagem além-fronteira. $\mathrm{E}$, com efeito, nos números seguintes da Gazeta, verifica-se a confirmação de que as últimas viagens teriam sido até à Galiza e Salamanca, com um sucesso tal que se aventava então a hipótese de um intercâmbio peninsular de excursões desta natureza.

Em setembro de 1933, tornava-se claro que a iniciativa dos Comboios Mistério tinha morrido, não tendo sequer sido organizadas excursões neste modelo nesse verão. Para compreendermos esta decisão, é, mais uma vez, necessário recorrer à Gazeta dos Caminhos de Ferro. É, novamente, o engenheiro Armando Ferreira, na sua rubrica "À Tabela”, que esclarece a questão. Num artigo de junho, quando se esperava que arrancasse o primeiro comboio mistério de 1933, Armando Ferreira retoma a sua posição inicial sobre a iniciativa, ao indicar que "o gosto do mistério, o ancestral apetite de marchar para o desconhecido é vencido, no século XX, pela excelsa vaidade de estar no segredo dos deuses", de tal forma que, "8 dias antes de sair do Rossio já o seu feliz passageiro sabe, ufano, para onde vai" (Ferreira, 1933a: 360). Mas o artigo revela-se interessante acima de tudo pela análise perspicaz que faz das potencialidades deste tipo de excursões. Assim, Armando Ferreira destaca desde logo os escassos proveitos económicos obtidos até à data com os comboios mistério, indicando mesmo que alguns teriam dado prejuízo. $O$ redator refere que, relativamente às excursões de 
1932, estas teriam sido frequentadas quase sempre pelos mesmos viajantes, que se "repetiam de semana para semana" (Ferreira, 1933a: 360); este seria, pois, mais um dos problemas da iniciativa. Por fim, destaca-se a ausência de estruturas turísticas de qualidade para receber condignamente estes viajantes, já que "Portugal, que é muito Grande, na História, no império colonial [... ] é infelizmente pequeno em Hotéis de $1^{\mathrm{a}}$, e comodidades turísticas de honrar uma excursão, [tornando-se difícil combinar] essas belezas do Portugal pitoresco com os quartos com água corrente e os encantos da jornada diurna com a dureza encaracolada dos colchões nocturnos" (Ferreira, 1933a: 360).

Por fim, de destacar o número total de 3000 viajantes nestes comboios mistério, referido, a título de síntese, por António Montês, chefe do Serviço de Turismo e Publicidade dos Caminhos de Ferro Portugueses, em junho de 1941, na Viagem, Revista de Turismo, Divulgação e Cultura, então editada com o patrocínio do Secretariado de Propaganda Nacional e do Conselho Nacional de Turismo.

\section{Os expressos populares}

Ao desaparecimento dos comboios mistério sucedeu-se nova iniciativa, os expressos populares da $\mathrm{CP}$, surgidos no verão de 1933. Este modelo de excursões ferroviárias destinava-se às classes baixas de Lisboa e Porto, realizando-se em carruagens de 3 a classe, "modernas, asseadas, de cómodo suficiente", onde, por uma tarifa única de 20 escudos por pessoa, aos menos abonados era possibilitado "experimentar a delícia da velocidade e a prontidão do serviço", oferecendo "um ócio aprazível a quem trabalha com ardor, toda a semana" (Maia, 1933:1). Os passeios, de ida e volta no mesmo dia, dirigindo-se a pontos pitorescos ou cidades históricas do país, realizavam-se normalmente aos domingos, sendo que cada excursionista poderia transportar consigo até dez quilogramas de farnel. O primeiro expresso realizou a viagem entre Lisboa e Tomar.

A iniciativa mereceu aprovação imediata e unânime dos meios turísticos nacionais, incluindo da Gazeta dos Caminhos de Ferro, onde o engenheiro Armando Ferreira via a ideia como "a confirmação do sintoma de vida nova", o quebrar do "narcisismo de importância dos potentados ferroviários", obrigados a "despertar, e vir cá baixo ao contacto do povinho, do senhor passageiro, adulá-lo, lisonjeá-lo e apregoar-lhe a mercadoria, [numa] procura do aumento de receitas" (Ferreira, 1933b: 442). Na mesma revista se manifestava Melo e Niza, para quem estas viagens seriam um "meio de contribuir para a educação do povo, mostrandoIhe as belezas dignas de nota" (Niza, 1933: 72), devendo apresentar "preços populares", com reduções de 50\% a 60\%, aos domingos e feriados. Claramente, repete-se o discurso que tinha já sustentado a iniciativa dos comboios mistério, um discurso onde predomina a tónica nacionalista, com o turismo a ser assumido como instrumento de nacionalização, "peça do jogo de encenação política do país" (Nunes, 2009: 55).

Os expressos populares ter-se-ão inspirado de forma clara nos treni festivi ou popolari criados pelo regime fascista italiano, para os italianos da classe média e para os operários, a partir de agosto de 1931 e vigorando até setembro de $1939 .{ }^{5}$ Estes eram comboios especiais, que saiam das principais cidades, ao domingo ou em feriados, retornando no mesmo dia, apenas com bilhetes de terceira classe e com um desconto, em relação à tarifa normal, de até $80 \%$, dirigindo-se a destinos turísticos relevantes do ponto de vista histórico, etnográfico,

\footnotetext{
5 Também em França existia uma iniciativa análoga, os trains Bonnet, desde 1904 e estendendo-se até 1939. Só com carruagens de $2^{\mathrm{a}}$ e $3^{\mathrm{a}}$ classes, estes comboios permitiam às classes mais desfavorecidas passar o verão na terra natal, usufruindo de descontos de $40 \%$. Esta iniciativa poderá ter igualmente servido de fonte de inspiração para os expressos populares dos caminhos-de-ferro portugueses.
} 
artístico, sem paragens intermédias. A iniciativa permitiu a centenas de italianos viajar pela primeira vez de comboio, possibilitando o turismo em massa na Itália, apesar de ter abrangido apenas uma pequena parte da classe média italiana, a que vivia nas grandes cidades e trabalhava nas fábricas e nos escritórios.

O sucesso atingido logo em 1931 - entre agosto e setembro foram feitas 495 viagens, transportando-se 459887 passageiros (Maggi, 2011) ${ }^{6}$ - chamou sobre si a atenção do poder político, em particular de Galeazzo Ciano, o ministro das Comunicações, desenvolvendo-se muito para lá das ambições iniciais da Ferrovie dello Stato, ignorando mesmo as questões de sustentabilidade financeira da companhia, como defende Cecini: "Le ragioni della politica, e segnatamente della politica del consenso, sopravanzavano del tutto quelle, assai più sevre, dell'economia" (Cecini, 2014: 127).

Tratava-se aqui, como o foi depois em Portugal, de uma iniciativa com objetivos políticos bem definidos. Assim, na Itália fascista o discurso oficial era inegavelmente claro: "Per dare modo a estese categorie di cittadini di compiere nei giorno festivi ed in particolari ricorrenza gite istruttive e di piacere che diffondano largamente la conescenza del nostro paese ed il godimento delle sue bellezze natural ed artistiche" (citado em Cecini, 2014: 115). Em Portugal, por seu turno, num regime com características muito semelhantes às da Itália mussoliniana, falava-se dos expressos populares como de uma "obra meritória [... ], reconstituinte do vigor e da alegria ao povo produtor e consumidor" (Maia, 1933: 1), algo que permitiria resolver um problema nacional, uma vez que "a maioria dos Portugueses, por lhe estar vedado pela falta de recursos, desconhece os encantos e belezas das nossas panorâmicas, a graça ingénua das nossas tradições, os usos e costumes, os monumentos e locais históricos, padrões gloriosos do nosso passado cheio de grandeza" ("Expressos Populares", 1939: 1).

Todavia, os números entre nós são menos espetaculares: nos primeiros três anos de existência, ter-se-ão transportado (apenas) 29000 viajantes. Pouco mais se sabe sobre a iniciativa: da consulta da Gazeta dos Caminhos de Ferro, é possível verificar que perdurou muito mais do que a sua antecessora, já que, em artigo de 1939, era considerada como "uma obra meritória, patriótica [... ] sempre com êxito crescente" ("Balanço de 1938", 1939: 72). Em 1952, novo artigo referindo-se aos expressos populares, organizados na época das férias e com destinos como Vila Viçosa, Évora, Santarém, Coimbra, Figueira da Foz, Porto ou Viana do Castelo. Aí se apontava a casa dos milhares em termos de afluência de viajantes, sendo que em artigo na revista Viagem de 1941 se apontava um número na casa dos 100000 viajantes.

\section{Considerações finais}

A geografia dos espaços turísticos nacionais era composta, até à instauração da República, por um pequeno conjunto de aglomerados e estâncias: 17 lugares que mereciam ser visitados e 19 águas minerais e praias principais, como referenciado na obra de Mendonça e Costa - Manual do Viajante em Portugal - editada pela Gazeta dos Caminhos de Ferro. Algo incipiente ainda, portanto. A efetiva turistização do território português, centrada em localidades pitorescas do ponto de vista etnográfico e de relevo histórico-cultural, é uma tarefa levada a cabo no Estado Novo, muito graças à expansão da rede ferroviária, que foi condicionando de forma clara o desenvolvimento turístico nacional, como confirmam Ferreira e Simões: "Cedo se evidencia, tanto na ótica da procura como da oferta, a importância dos caminhos-de-ferro na mobilização

\footnotetext{
${ }^{6}$ Este número de 1931 foi em crescendo até 1938: 833943 passageiros em 1932; 864297 no ano seguinte; 1030388 em 1934; 1064262 em 1935; 1195571 em 1936, passando já a casa do 1200000 nos dois anos seguintes. No total da sua existência, os comboios populares transportaram em Itália 8774451 passageiros, de acordo com os dados da Ferrovie dello Stato (Giuntini, 2002).
} 
dos fluxos, tanto internos como internacionais, para os diferentes lugares/estâncias turísticos de Portugal" (Ferreira \& Simões, 2010: 78).

Talvez por isto, em 1941, António Montês, chefe do Serviço de Turismo e Publicidade da Companhia de Caminhos de Ferro Portugueses, afirmasse: "Quando em Portugal se falar em turismo, há-de reconhecer-se que a C.P. tem contribuído poderosamente para o seu desenvolvimento" (Montês, 1941: 4). Efetivamente, a CP distinguiu-se desde cedo no que à comodidade, economia e rapidez da sua oferta dizia respeito, sabendo que, "sem eles a palavra Turismo é letra morta [uma vez que] as exigências da época não resistem às deficiências dos meios de transportes ou à falta de comodidades" ("Expressos Populares", 1939: 1).

Mas, embora o investimento no setor turístico tenha sido diverso na I República e no Estado Novo, a conceção de turismo assemelhava-se, verificando-se uma continuidade, pela permanência de uma relação estreita entre Turismo e Patriotismo nos discursos políticos oficiais, quer dos republicanos, quer dos salazaristas (Vidal \& Aurindo, 2010). Desta forma, o turismo, equivalente na I República à digressão cultural, isto é, o excursionismo com visita a monumentos e locais célebres da Nação, enquadrava-se no programa político-ideológico do regime, "que procurou fomentar os sentimentos patrióticos, elevar pela educação o espírito das populações e, com tudo isso, produzir cidadãos empenhados no progresso do País" (Henriques \& Lousada, 2010: 108). Já com o Estado Novo, nos anos trinta, o Presidente do Conselho relembrava regularmente a necessidade de se conhecer o território português para se amar a Nação, "no seu passado de grandeza heróica, no seu presente de possibilidades materiais e morais, adivinhá-lo no seu futuro de progresso, de beleza, de harmonia", possibilitando este conhecimento um "são nacionalismo" (citado em Cadavez, 2012: 80). O discurso político persistia e renovava-se, embora num quadro político diferente, assente na dimensão político-educativa dada ao turismo, que permitiria colmatar a necessidade de tornar Portugal conhecido dos portugueses.

Neste sentido, concorda-se com Vidal e Aurindo quando referem que o turismo, "antes de ser uma indústria lucrativa [...], surge como um discurso ou um conjunto de discursos: maneiras de olhar, sentir, apreender e representar os territórios" (Vidal \& Aurindo, 2010: 119), em íntima associação com práticas de construção identitárias. Entre nós, os usos políticoideológicos do turismo, quer na I República quer, sobretudo, no Estado Novo, constituíram momentos importantes para a construção de uma certa ideia da Nação, elemento constituinte de programas de nacionalização das massas, apelando ao sentimento e à emoção coletiva.

Sendo essenciais as acessibilidades internas para a prática do turismo, o caminho-de-ferro foi um setor privilegiado na política de transportes do Estado Novo, tornando-se crucial para o desenvolvimento turístico do país, mas, igualmente, para a coesão nacional. Com efeito, as viagens ferroviárias dos comboios mistério e dos expressos populares assumiram a tarefa de disseminação da consciência nacional, do sentimento patriótico, da esfera pública para o plano do quotidiano das populações. Tal liga-se ao conceito desenvolvido por Michael Billig (1995) de "nacionalismo banal", um nacionalismo que se reproduz no dia-a-dia, tomando a Nação como facto adquirido, contribuindo, desta forma, para naturalizar a sua existência.

Em paralelo, estas viagens pretendiam fomentar o turismo interno, numa aposta num público-alvo constituído essencialmente pelas classes médias-baixas, dado o seu caráter económico, com claras vantagens para o setor: desde logo pelas possibilidades de crescimento dos serviços de transporte terrestre, que apoiavam/complementavam em determinadas etapas estas excursões ferroviárias, e, claro, das organizações hoteleiras regionais, que viam o fluxo de hóspedes crescer, mesmo que de forma esporádica e sazonal. Também as próprias localidades visitadas sentiram os efeitos benéficos da passagem destes excursionistas. 
Todavia, com a guerra civil de Espanha e o início da II Guerra Mundial, começava novo período de dificuldades para o turismo português. Durante esse tempo, Portugal comemorou, longe das hostilidades, os Centenários, promovendo a Exposição do Mundo Português, tendo vivido uma franca redução de entradas de turistas no país. No pós guerra, a Companhia de Caminhos de Ferro Portugueses retomou, a partir de 1948, as suas excursões turísticas, em colaboração com a empresa Wagons Lits, o Secretariado Nacional de Informação e as comissões de turismo locais. Organizadas em formato semanal, estes passeios procuravam levar as classes médias a várias cidades portuguesas, de forma a "intensificar o gosto pelas viagens através do País [... ] no intuito de tornar mais conhecidas as paisagens e monumentos" ("As excursões turísticas", 1948: 4). Nada de novo, portanto: pugnava-se pela descoberta de Portugal pelos portugueses, que parecia ainda não se ter concretizado.

\section{Referências bibliográficas}

Almeida, A. F. (1932, 16 setembro). As iniciativas da C.P. O nono comboio mistério. Gazeta dos Caminhos de Ferro, 1074, p. 428.

Ataíde, J. (1931, janeiro). O Turismo no ressurgimento do País. A.C.P. Revista llustrada de Automobilismo e Turismo, 4, p. 18.

Billig, M. (1995). Banal nationalism. London: Sage Publications.

Cadavez, M. C. P. (2012). A bem da nação. As representações turísticas no Estado Novo entre 1933 e 1940 (Tese de Doutoramento). Faculdade de Letras da Universidade de Lisboa, Lisboa.

Cecini, S. (2014). Il treno per tutti. Gli italiani in gita con i treni populari 1931-1939. Dimensioni e problemi della ricerca storica, 2, 113-138.

Correia, R. (2009). Gazeta dos Caminhos de Ferro (1888-1971). Lisboa: Câmara Municipal de Lisboa.

Costa, C. M. (1932, 16 julho). O turismo e os caminhos de ferro. Gazeta dos Caminhos de Ferro, 1070, pp. 336-337.

Ferreira, A. (1932a, 16 março). Excursões. Gazeta dos Caminhos de Ferro, 1062, p. 144.

Ferreira, A. (1932b, 16 junho). VIII-Mistério. Gazeta dos Caminhos de Ferro, 1068, p. 280.

Ferreira, A. (1932C, 1 julho). IX-Viajar. Gazeta dos Caminhos de Ferro, 1069, p. 304.

Ferreira, A. (1933a, 16 junho). A atracção do mistério. Gazeta dos Caminhos de Ferro, 1092, p. 360.

Ferreira, A. (1933b, 1 agosto). Os Expressos Populares. Gazeta dos Caminhos de Ferro, 1095, p. 442.

Ferreira, C. C. \& Simões, J. M. (2010). Portugal turístico ao tempo da I República: Espaços, lugares e projetos. In M. A. Lousada \& A. P. Pires (Eds.), Viajar. Viajantes e turistas à descoberta de Portugal no tempo da I República (pp. 77-98). Lisboa: Comissão Nacional para as Comemorações do Centenário da República.

Ferro, A. (1939, 22 novembro). Turismo como factor político. Diário de Notícias, p. 1.

Ferro, A. (1949). Turismo. Fonte de Riqueza e de Poesia. Lisboa: SNI.

Fonseca, J. (1932, abril). Portugal, País de turismo. A.C.P. Revista llustrada de Automobilismo e Turismo, 19, p. 39.

Gaspar, J. N. (1932, 1 setembro). O sétimo comboio mistério. Crónica de dois dias enigmáticos. Gazeta dos Caminhos de Ferro, 1073, pp. 405-407.

Giuntini, A. (2002). Ferrocarriles y turismo en Italia desde los inicios del ochocientos hasta la introducción de los 'trenes populares' en la época fascista. Historia Contemporánea, 25, 101-123.

Henriques, E. B. \& Lousada, M. A. (2010). Férias em Portugal no primeiro quartel do século XX. A arte de ser turista. In M. A. Lousada \& A. P. Pires (Eds.), Viajar. Viajantes e turistas à descoberta de Portugal no tempo da I República (pp. 105-117). Lisboa: Comissão Nacional para as Comemorações do Centenário da República e Turismo de Portugal.

Maggi, S. (2011). A new role for an old railway: Tourism. In A. Mccants, E. Beira, J. L. M. Cordeiro \& P. B. Lourenço (Eds.). Railroads in historical context: Construction, cost and consequences (vol. I, pp. 427443). Vila Nova de Gaia: Inovatec.

Maia, S. (1933, 27 julho). Os expressos populares. O Século, p. 1.

Manso, J. (1933, 8 agosto). Ar livre. O amor das viagens. Diário de Lisboa, p 1.

Matos, A. C. (2014). Turismo, guias e roteiros. In M.F. Rollo (Eds.) Dicionário de história da I República e do Republicanismo (vol. III, pp. 1017-1022). Lisboa: Assembleia da República. 
Matos, A. C., Ribeiro, E. F. \& Benardo, M. A. (2009). Caminhos-de-Ferro e Turismo em Portugal (final do século XIX e primeiras décadas do século XX). Comunicação apresentada no V Congresso de História Ferroviária, Palma de Maiorca.

Montês, A. (1941, junho). Viagens de turismo para portugueses. Viagem, Revista de Turismo, Divulgação e Cultura, 8, 3-4.

Niza, A. M. (1933, 1 fevereiro). Comboios populares. Gazeta dos Caminhos de Ferro, 1083, p. 72.

Nunes, C. M. (2009) Figueira da Foz (1930-1960). Apontamentos sobre o turismo balnear. (Dissertação de Mestrado não publicada). Faculdade de Letras da Universidade de Coimbra, Coimbra.

Richez, J. C. \& Strauss, L. (2001). Um tempo novo para os operários: As férias pagas (1930-1960). In A. Corbin. História dos Tempos Livres (pp. 458-503). Lisboa: Teorema.

s.a. (1939, 16 janeiro). Balanço de 1938. Gazeta dos Caminhos de Ferro, 1226, p. 72.

s.a. (1939, maio-junho). Expressos populares. Viagem. Revista de Turismo, Divulgação e Cultura, 8, p. 1.

s.a. (1948, 16 abril). As excursões turísticas organizadas pela C.P. Diário de Notícias, p. 4.

Sabel (1932, 1 julho). Iniciativas modernas. Gazeta dos Caminhos de Ferro, 1069, p. 315.

Thiesse, A. -M. (2001). Organização dos lazeres dos trabalhadores e tempos roubados (1880-1930) In A. Corbin (Ed.), História dos tempos livres (pp. 367-391). Lisboa: Teorema.

(1932, 15 junho). Uma iniciativa original da C.P. Diário de Notícias, p. 1.

Valente, J. C. (2010). Para a história dos tempos livres em Portugal: da FNAT à INATEL (1935-2010). Lisboa: Edições Colibri/Fundação INATEL.

Vidal, F. \& Aurindo, M. J. (2010). Turismo e identidade nacional: Uma nova imagem para Portugal. In M. A. Lousada \& A. P. Pires (Eds.) Viajar. Viajantes e turistas à descoberta de Portugal no tempo da I República (pp. 119-125). Lisboa: Comissão Nacional para as Comemorações do Centenário da República e Turismo de Portugal.

CARLA RIBEIRO é Doutora em História Contemporânea, pela Faculdade de Letras da Universidade do Porto, com a tese Imagens e representações de Portugal. António Ferro e a elaboração identitária da Nação. Professora Adjunta na Escola Superior de Educação do Politécnico do Porto. Investigadora do CEPESE - Centro de Estudos da População, Economia e Sociedade (Universidade do Porto) e do InEd - Centro de Investigação e Inovação em Educação (Escola Superior de Educação do Politécnico do Porto). Tem como áreas de interesse e investigação, no âmbito da História cultural contemporânea, as políticas e os organismos culturais do Estado Novo, o cinema português e o turismo no Estado Novo e os estudos folcloristas portugueses nos séculos XIX e XX, em ligação com as questões de identidade nacional. Endereço institucional: Escola Superior de Educação do Politécnico do Porto, Rua Dr. Roberto Frias, 602, 4200-465 Porto, Portugal.

Submetido em 15 setembro 2016

Aceite em 28 março 2017 